\title{
Proceeding
}

Supplementary Issue: Autumn Conferences of Sports Science. Costa Blanca Sports Science Events, 18-19 December 2020. Alicante, Spain.

\section{Physical education classes with distance learning as a catalyst for adaptation potential increase of students during the COVID-19 pandemic}

\author{
ELENA FAZLEEVA, DMITRII TUMAKOV $\triangle$, ALSU VALEEVA, ROALD AKBEROV \\ Kazan Federal University, Russian Federation
}

\begin{abstract}
Physical education classes at all Russian universities are mandatory and held during the first, second and third years of studying for a bachelor's degree. In connection with switching to distance learning during the COVID-19 pandemic, the investigated students of Kazan Federal University were engaged in both online physical education classes and self-study physical education classes with the obligatory keeping of a self-monitoring diary, which allowed tracking the dynamics of changes in psycho-emotional, functional states as well as physical fitness. As part of the educational process, teachers and students contacted through the Microsoft Teams platform, where classes and consultations were held; information and control materials were exchanged. A control group and an experimental group were formed with 90 students in each of the groups totalling 180 students. Each of the groups included 30 students of the main subgroup (healthy), 30 students of the preparatory subgroup (with minor deviations in health), and 30 students of the special medical subgroup with confirmed diseases of various nosology. In the control group, the students were engaged in physical education classes, fulfilling the general requirements: they filled out a self-monitoring diary, carried out the recommended tests to assess functional and physical fitness. Calculation of "working pulse rate" according to Karvonen's formula gave students the opportunity to determine and select the amount and intensity of physical activity in the process of self-study. According to the self-monitoring diaries, the students showed positive dynamics in the psycho-emotional state. Students also noted the interdependence of their mood, well-being, desire to learn and be active on the quantity and quality of physical education classes. Exercises of sufficient intensity improved mood, relieved feelings of anxiety, and increased the positivity of perception of the surrounding environment. For ten weeks of distance learning, the students of the experimental group, whose physical activity was regulated individually, and the intensity of the load was selected with account of peculiarities of the work of their functional systems, showed a value of adaptation potential higher than that of students of the control group.

Keywords: Physical education; Distance learning; Adaptation potential; COVID-19; Pandemic.
\end{abstract}

Cite this article as:

Fazleeva, E., Tumakov, D., Valeeva, A., \& Akberov, R. (2021). Physical education classes with distance learning as a catalyst for adaptation potential increase of students during the COVID-19 pandemic. Journal of Human Sport and Exercise, 16(2proc), S410-S420. doi:https://doi.org/10.14198//hse.2021.16.Proc2.26

Corresponding author. Kazan Federal University, Russian Federation. https://orcid.org/0000-0003-0564-8335

E-mail: d.research_r@yahoo.com

Abstract submitted to: Autumn Conferences of Sports Science. Costa Blanca Sports Science Events, 18-19 December 2020. Alicante, Spain.

JOURNAL OF HUMAN SPORT \& EXERCISE ISSN 1988-5202

(c) Faculty of Education. University of Alicante

doi:10.14198/jhse.2021.16.Proc2.26 


\section{INTRODUCTION}

Studying the issues related to adaptation of people to changing surrounding conditions such as economic, social, cultural, etc. is always of high importance and requires the search for simple but efficient means that optimize a complex set of psychophysiological adaptive reactions of the human organism to the changes. The relevance of this study is objectively confirmed by recent events associated with the COVID-19 pandemic driven by the SARS-CoV-2 coronavirus. During the pandemic, people all over the world switched from the ordinary rhythm of life to the self-isolation regime, which led not only to minimizing the physical activity (Lippi et al., 2020; Alexandrov, 2020; Milko \& Guremina, 2020; Hammami et al., 2020; Nikolaou \& Markogiannakis, 2017); but also to the occurrence of psycho-emotional stress, asthenia, panic attacks on the background of the general information load from mass media associated with the threat of contracting a new viral infection (Hyland et al., 2020; Mattioli, et al., 2020; Narici et al., 2020; Zhao et al., 2020; Shevlin et al., 2020; Özdin \& Bayrak Özdin, 2020; Cao et al., 2020; Kholodova, 2020). In our previous studies performed before the COVID-19 pandemic (Tumakov et al., 2017; Tumakov et al., 2018; Tumakov et al., 2019), we carried out a number of investigations over undergraduate students of Kazan Federal University (KFU), which is one of the leading universities of Russia. For instance, we analysed in detail a wide range of issues associated with various aspects of students' adaptation to the learning environment, built mathematical models reflecting the options for adaptation processes in students and performed some other important investigations. The essential point of the aforementioned studies is that the physical education classes at all Russian universities are mandatory (in comparison with universities located elsewhere in the world). They are held twice a week (every class lasts two academic hours) during the first, second and third years of studying at the university for a bachelor's degree. It is noteworthy that no such thing as distance learning for physical education classes has ever been employed at Russian universities prior to appearance of the COVID-19 pandemic.

In the aforementioned studies, we indicated that significant reserves for improving the efficiency of adaptation of undergraduate students at Russian universities to changing external conditions lie in the field of students' physical activity (Fazleeva et al., 2016). Indeed, physical activity is a powerful means of restoring students' mental and physical strength, optimizing the complex multi-factor process of adaptation not only to new conditions of learning activity, but also to the life in general (Vasenkov \& Fazleeva, 2013; Grutsyak \& Grutsyak, 2010; Pavlov, 2001; Noraseela et al., 2016). Physical activity indirectly, but efficiently affects the improvement of the adaptation process through reducing stress, relieving symptoms of depression and anxiety, increasing self-esteem (Dubbert, 2002; Dunn et al., 2002; Callaghan, 2004). Regular physical education classes also reduce the risk of the onset and progression of a number of diseases (American College of Sports Medicine, 2006; Myers et al., 2004; Zaitseva, 2020), which has a beneficial effect on the overall health of students.

Unlike our previous investigations, in the present study we intend to solve several somewhat different tasks. The tasks include determining the influence of motor activity on the state of students' adaptive systems, tracking the dynamics of adaptation potential changes with a change in physiologically sound choice of load intensity, evaluating the influence of regular physical activity on changes in subjective assessments of students' psycho-emotional state. In addition, we aim to provide guidelines for using the self-monitoring methods and assessing the physical, functional, and psycho-emotional states.

\section{Organizing the physical education classes with distance learning}

Since students had to switch to distance learning due to the need for self-isolation caused by rapid spread of the coronavirus, we made efforts to develop recommendations for organizing both online physical education classes and self-study classes with the obligatory keeping of a self-monitoring diary for tracking the dynamics 
of changes in psycho-emotional states, functional states, and physical fitness. As part of the educational process, teachers and students contacted through the Microsoft Teams platform, through which the physical education classes (twice a week according to the schedule) and consultations were held; information and control materials were exchanged.

The contingent of students, whose contact physical education classes were switched to the remote platform, is heterogeneous in terms of physical fitness and health indicators.

Before starting the first year, all students had to pass a mandatory medical examination at the university health clinic and based on the results of the examination, the students were divided into groups for physical education classes in accordance with the recommendations from doctors of the health clinic. Students, who did not have contraindications for physical education classes, were enrolled in the "main" group. Students having slight restrictions on the motor regime of classes were recommended to study in the "preparatory" group. Students with chronic illnesses, who were prescribed a sparing regime of physical education for medical reasons, were recommended to study in a "special medical" group.

It must be emphasized that the goal of practical and methodological training in physical education classes at a Russian university is not only to increase the level of students' physical and functional fitness, i.e., the classes are not simply training sessions like in an afterschool sports club or in a fitness centre. The tasks of teaching in physical education classes are much wider. It is important for teachers to give students the most complete information about the means and methods of physical education, about how they are used, what results can be achieved, how they can be adjusted and to create algorithms for individual classes, of course, reinforcing all this with practical skills. In other words, we strive to satisfy the needs of young people in obtaining socially significant information in the field of physical culture and sports, to teach them how to operate in accordance with their own interests, with individual characteristics and state of health.

Distance learning has made significant adjustments to the content of both training sessions and self-study physical education classes according to quantitative (time) and qualitative (intensity) criteria (Levina, 2020; Beato \& Silveira, 2018). At the training sessions, the amount of the methodological component increased, since not all students had the opportunity to actively move during online classes due to technical (lack of a stable Internet signal) and domestic (not enough space) reasons. Since during the scheduled online training sessions the amount of physical activity was small and could not compensate for the increase in the manifestations of hypodynamic, we moved the main training component to self-study classes (held at least twice a week).

This allowed solving the problem with achieving the physiologically necessary amount of physical activity: after all, when organizing self-study classes that do not require an Internet signal, students could individually organize their workouts in accordance with their state of health, level of physical fitness and certain domestic conditions.

All students during the distance learning were required to conduct self-monitoring of their condition twice a week in accordance with the schedule of their physical education classes. In the self-monitoring diaries, students recorded the following subjective indicators: well-being, desire to work, quality of sleep, appetite, pulse rate (at rest (lying in the morning for $1 \mathrm{~min}$ ), before class, during class (every 20 minutes), after class), as well as indicated the weekly amount of motor activity. The filled anthropometry data were height, weight, blood pressure, body-weight index and target working pulse rate (calculated via the Karvonen formula (Karvonen et al., 1957)). Functional tests performed every two weeks were orthostatic, clinostatic and Ruffier 
test (Tumakov et al., 2018). The results of physical preparation, which included lifting the body from a prone position, push-ups, and flexibility, were recorded on a monthly basis.

\section{Recommendations for physical load for self-studies with account of loads intensity}

During the distance learning, the physical education teacher objectively had no ability to regulate and control the amount of load received by the students during each class. Therefore, in the methodological recommendations for conducting self-studies and keeping a self-monitoring diary, students were recommended to use the Karvonen formula to determine the "working pulse rate", the calculation of which allows to individually select and plan the intensity of the load for classes.

For example, we recommend that a student of a special medical group begin classes with a load of low intensity.

The main goal of classes for students with poor health is to train the cardiovascular system (cardio workout), and these students need to work at a heartbeat rate (HBR) of $40-60 \%$ of the maximum HBR. Hereinafter, the terms "heartbeat rate" and "pulse rate" will be considered as interchangeable.

Calculation of the working pulse rate by the Karvonen formula:

$$
\mathrm{HBRw}=[(220-\text { age })-\mathrm{HBRr}] \times \mathrm{PIL}+\mathrm{HBRr}
$$

where HBRr is pulse rate recommended for cardio workouts.

$\mathrm{HBRr}$ is pulse rate at rest (it must be measured in the morning after waking up or after 15 minutes of complete relaxation).

PIL is planned intensity of load, i.e., in our case its value ranges from 40 to $60 \%$. In the formula, we do not use the percent sign $\%$ and therefore the coefficient will be in the range from 0.4 to 0.6 .

The maximum heartbeat rate is usually calculated by the formula (220-age); therefore, in the formula we take into account the age.

For example, we need to calculate the "working pulse rate" for a 20 -year-old female who is recommended to do jogging. We calculate the upper and lower bounds, i.e., $40 \%$ and $60 \%$ of the maximum HBR. Pulse rate at rest is 70 beats per minute.

$\mathrm{HBRw}=[(220-20)-70] \times 0.4+70=122$ beats $/ \mathrm{min}$. This pulse rate will constitute the lower bound.

$\mathrm{HBRw}=[(220-20)-70] \times 0.6+70=148$ beats $/ \mathrm{min}$. This pulse rate will constitute the upper bound

Thus, for training the cardiovascular system, the student needs to have the pulse rate of $122-148$ beats $/ \mathrm{min}$. We emphasize that the heartbeat rate must be increased gradually. Measurement of the pulse rate is carried out in 3-5 minutes after the beginning of cardio workout, then as necessary or if the student feels well. Certainly, for a student with poor health, to have training in a specified intensity zone at this stage of classes with a gradual increase in heartbeat rate values at loading to the upper bound of the indicated corridor of values will be optimal. 
It is clear that for students with higher health indicators (preparatory and main groups), loads of higher intensities should be recommended.

The Karvonen method shows some averaged values of training zones, and it is not absolutely accurate, but as a guideline for determining the load intensity, it works just fine.

According to the available classification that is based on the ranges of heartbeat rate indicators, five zones of training load intensity are usually distinguished (Swaim, 2012).

Aerobic recovery zone (zone 1 , healthy heart zone). The load intensity of $40-60 \%$ or $50-60 \%$ (of the maximum heartbeat rate) is considered suitable for warming up, restoring the body and for those who are just starting physical education classes. These pulse rate values correspond to the pulse rates during a normal walk.

Aerobic developing zone (zone 2, temperate zone), i.e., a moderate intensity exercise zone $-60-70 \%$ of maximum heartbeat rate. In this zone, active fat burning begins.

Mixed aerobic-anaerobic zone (zone 3, aerobic zone), i.e., a high intensity load zone $-70-80 \%$ of maximum heartbeat rate. Intensive fat burning occurs in this zone and endurance develops.

Anaerobic-glycolytic zone (zone 4, threshold zone), i.e., a submaximal intensity load zone - $80-90 \%$ of maximum heartbeat rate. The development of physical endurance takes place.

Anaerobic-lactate zone (zone 5 , red line zone), i.e., a maximum intensity load zone. Heartbeat rate indicators are $90-100 \%$ of the maximum heartbeat rate.

\section{RESULTS AND DISCUSSION}

From students involved in distance learning, we formed two groups of the Institute of Philology and Intercultural Communication of KFU, namely a virtual control group consisting of 90 students and an experimental group also consisting of 90 students with the total number of students in the two groups equal to 180. Each of the groups included 30 students of the main group (practically healthy), 30 students of the preparatory group (with slight disorders in health condition), and 30 students of the special group with confirmed diseases of various nosology.

In the control groups, students were engaged in physical education, fulfilling the general requirements: they filled out a self-monitoring diary, conducted recommended tests to assess functional and physical fitness. Calculation of the "working pulse rate" according to the Karvonen formula gave students the opportunity to determine and select the amount and intensity of physical activity in the self-study process.

An analysis of the pulse rate dynamics data of students in control groups, reflected in self-monitoring diaries, showed that only $38 \%$ of students in the main group arranged their classes in accordance with individual data obtained by calculating the "working pulse rate" zone using the Karvonen formula. These students not only studied in the recommended zones, but also adhered to the dynamics of increasing the load. Students of the preparatory group showed a similar result $-39 \%$. Most students of a special medical group chose a less intensive load for classes (stretching in combination with breathing exercises; walking), therefore only $26 \%$ of students provided reports on training in the "working pulse rate" zone with progressive dynamics. 
In the experimental group, the requirements for the performance of motor tasks in the process of self-studies were set not in a recommendatory form, but rather in a requirement form. After students self-assessed the functional indicators of the cardiovascular system and provided data to the teacher, the students were given individual instructions: what pulse rate value they need to achieve during the classes, how much time they need to be trained with maintaining such a heartbeat rate, by how much and when it is permissible to increase the load.

When developing recommendations for students on alternation and duration of exercises in each intensity zone during physical education, we focused on works of several researchers (Baronenko \& Rapoport, 2013).

In the aerobic recovery zone of the lowest intensity load, one can work for a long time: from 15 minutes to several hours. However, the effect of training will be observed only among the weakest and most unprepared students. Therefore, we most often use this load zone for warming up or for restoring functional indicators after physical education classes.

Training in the moderate intensity load zone, i.e., aerobic developing zone can last from 20-30 minutes to two or more hours.

Work of high intensity in a mixed aerobic-anaerobic zone lasts at least 3-5 minutes and does not exceed 2030 minutes. It is a fairly high load.

In the zone of submaximal intensity, work lasts from 20-30 seconds to 3-5 minutes.

In the zone of maximum intensity, the duration of work usually does not exceed 20-30 seconds. An example of such a load is short distance running; $50 \mathrm{~m}$ swimming; $500 \mathrm{~m}$ bike race, lifting and holding the bar of maximum weight. Most often, this is a competitive load, sprints, etc. During a regular training session, a student with a very high level of physical fitness can perform such a load several times.

When planning the workload for students, we also took into account the fact that the duration of a physical education class is 90 minutes, and the time for a self-study during extracurricular hours can be increased to 120 minutes.

Studying the level of psycho-emotional state of students using the HAM method (health, activity, and mood) (Il'in, 2005) showed that the level of students' health at the beginning of the distance learning period approaches the lower limit of average values (average score is 4.17). The results according to the criteria "mood" and "activity" are also low, which are equal to 3.98 and 4.05, respectively. Such results indicate an unstable state and are explained by an increase in the level of anxiety, instability of the general situation, a sharp change in living and learning conditions, strict requirements for self-isolation, uncertainty in terms of the perspectives for the development of events, etc.

Thereafter, we tracked subjective assessments of indicators of mood, health, and activity according to the data in self-monitoring diaries of the students.

Thus, after revealing that due to changes in the epidemiological situation that dramatically had changed the usual way of life and study, psycho-emotional stress and anxiety of students increased. Based on the data from self-monitoring diaries, reflecting the individual dynamics of functional indicators (HBR, arterial blood pressure (ABP), etc.), we suggested that the students of the experimental group dose the regime of motor 
loads, controlling their intensity. Since, in our opinion, such physical education classes will not only improve the psycho-emotional state, but also have both a stimulating effect on the operation of functional systems and optimization of the adaptive capabilities of the human organism as a whole.

We provided individually to each student in a chat our recommendations on selecting the load intensity as well as recommendations on its dynamics. In a general averaged form, data on the time boundaries of the intensity zones, which must be adhered to in the process of self-study in physical education classes for students with different levels of health, functional condition, and physical fitness, are presented in Table 1.

Table 1. Total duration of stay in the load intensity zones during one session.

\begin{tabular}{|c|c|c|c|c|c|}
\hline \multirow{2}{*}{$\begin{array}{l}\text { Groups of } \\
\text { students } \\
\text { differentiated for } \\
\text { medical reasons }\end{array}$} & \multicolumn{5}{|c|}{$\begin{array}{l}\text { Recommended total duration of stay in load intensity zones per session (in } \\
\text { minutes) }\end{array}$} \\
\hline & $\begin{array}{l}\text { Aerobic } \\
\text { recovery }\end{array}$ & $\begin{array}{c}\text { Aerobic } \\
\text { developing }\end{array}$ & $\begin{array}{l}\text { Mixed aerobic- } \\
\text { anaerobic }\end{array}$ & $\begin{array}{l}\text { Anaerobic } \\
\text { glycolytic }\end{array}$ & $\begin{array}{c}\text { Anaerobic } \\
\text { lactate }\end{array}$ \\
\hline Special & $25-60$ & $15-30$ & $4-10$ & & \\
\hline Preparatory & $40-90$ & $25-45$ & $8-20$ & $2-5$ & \\
\hline Main & $60-120$ & $30-60$ & $12-30$ & $4-10$ & $40 "-3$ \\
\hline
\end{tabular}

Certainly, the intensity should increase gradually, and the inclusion of the load from higher zones should be interval (i.e., alternation of the load intervals of high and low intensity). At the same time, constant monitoring of functional indicators (HBR, $A B P$, etc.) is necessary, which can be used to determine how the functional systems of the organism are trained and how the formation of adaptive reserves occurs.

The adaptive capabilities of a living system represent one of the fundamental properties of an organism, a criterion of its health level, as well as an indicator of its viability (Kershengolts \& Kolosova, 2016). Therefore, we consider this integrative criterion as most informative for studying the dynamics of the state of the functional systems of the organisms of students involved in physical education (Tumakov et al., 2018). To determine the state of adaptive capabilities and their dynamics in students in the control group, we used the method of qualitative and quantitative assessment proposed by R.M. Bayevsky and identified four levels of adaptation as follows: "satisfactory adaptation", "tension of adaptation", "unsatisfactory adaptation" and "adaptation failure" (Tumakov et al., 2018; Baevsky, 1987).

The level of adaptation was evaluated by the value of the adaptation potential (AP), which is calculated by the following formula:

AP (in points) $=0.011(\mathrm{HBR})+0.014(\mathrm{SAP})+0.008(\mathrm{DAP})+0.014$ (age in years) +0.009 (body weight, $\mathrm{kg})$ -0.009 (body length, cm) -0.27 ,

Where HBR is heartbeat rate (per minute); SAP is systolic arterial pressure $(\mathrm{mm} \mathrm{Hg})$; DAP is diastolic arterial pressure $(\mathrm{mm} \mathrm{Hg})$. All values of indicators are taken from self-monitoring diaries of students in the control and experimental groups.

Table 2 lists the calculations data after three measurements, which are most informative for our study. The control group worked in the normal mode and the students of the group determined the amount of loads on their own. The experimental group worked with the control of dynamics of the load's intensity. 
Table 2. Dynamics of adaptation potential of students during distance learning from 23.03 .2020 until 31.05 .2020 .

\begin{tabular}{|c|c|c|c|c|c|c|c|c|c|c|c|}
\hline \multirow{3}{*}{$\begin{array}{l}\text { Serial number } \\
\text { indicating time } \\
\text { point }\end{array}$} & \multirow{2}{*}{\multicolumn{3}{|c|}{$\begin{array}{l}\text { Number of } \\
\text { students in } \\
\text { various groups }\end{array}$}} & \multicolumn{8}{|c|}{ Number of students for each level of adaption in various groups } \\
\hline & & & & \multicolumn{2}{|c|}{$\begin{array}{l}\text { I } \\
\text { Satisfactory } \\
\text { adaptation } \\
\mathrm{AP} \leq 2.10\end{array}$} & \multicolumn{2}{|c|}{$\begin{array}{l}\text { II } \\
\text { Tension of } \\
\text { adaptation } \\
\mathrm{AP}=2.11 \ldots 3.20\end{array}$} & \multicolumn{2}{|c|}{$\begin{array}{l}\text { III } \\
\text { Unsatisfactory } \\
\text { adaptation } \\
\mathrm{AP}=3.21 . . .4 .30\end{array}$} & \multicolumn{2}{|c|}{$\begin{array}{l}\text { IV } \\
\text { Adaptation } \\
\text { failure } \\
\mathrm{AP} \geq 4.30\end{array}$} \\
\hline & $\begin{array}{l}\text { Group } \\
\text { type for } \\
\text { medical } \\
\text { reason }\end{array}$ & C. & E. & C. & E. & C. & E. & C. & $\mathrm{E}$. & C. & E. \\
\hline \multirow{3}{*}{$\begin{array}{l}1 \text { (Beginning of } \\
\text { distance learning } \\
\text { period) }\end{array}$} & Main & & & 22 & 20 & 6 & 7 & 2 & 2 & 0 & 1 \\
\hline & Prep. & 30 & 30 & 18 & 19 & 8 & 9 & 3 & 2 & 1 & 0 \\
\hline & Spec. & & & 14 & 15 & 9 & 9 & 5 & 4 & 2 & 2 \\
\hline \multirow{3}{*}{$\begin{array}{l}2 \text { (Middle of } \\
\text { distance learning } \\
\text { period) }\end{array}$} & Main & & & 15 & 19 & 11 & 8 & 3 & 3 & 1 & 0 \\
\hline & Prep. & 30 & 30 & 11 & 19 & 12 & 8 & 4 & 3 & 3 & 0 \\
\hline & Spec. & & & 9 & 14 & 14 & 10 & 4 & 2 & 3 & 0 \\
\hline \multirow{3}{*}{$\begin{array}{l}3 \text { (End of semester } \\
\text { and end of distance } \\
\text { learning period) }\end{array}$} & Main & & & 18 & 23 & 11 & 6 & 1 & 1 & 0 & 0 \\
\hline & Prep. & 30 & 30 & 14 & 23 & 12 & 6 & 3 & 1 & 1 & 0 \\
\hline & Spec. & & & 12 & 20 & 12 & 7 & 4 & 1 & 2 & 0 \\
\hline
\end{tabular}

Note: $\mathrm{C} .=$ Control group. $\mathrm{E} .=$ Experimental group.

As can be seen from the calculations, for a relatively short period of distance learning, students of the experimental group, for whom physical activity was individually regulated and the loads intensity was selected with account of peculiarities of their functional systems, showed a higher level of adaptation in comparison with students of the control group.

It is also worth noting the positive dynamics in the psycho-emotional state of students, the dynamics of which was tracked through the self-monitoring diaries. Students of the control and experimental groups reported the interdependence of their mood, health, desire to learn and to be active on the quantity and quality of physical education classes. Classes of sufficient intensity improved mood, relieved anxiety, and increased the positive perception of the world. Students reported normalization of sleep and appetite.

\section{CONCLUSIONS}

From the students switched to distance learning, one control group and one experimental group were formed with 90 students in each of the groups totalling 180 students. Each of the groups included 30 students of the main group, 30 students of the preparatory group, and 30 students of the special medical group with various diseases. In the control group, the students were engaged in physical education classes assessing their heartbeat rate according to Karvonen's formula.

The analysis of data on the dynamics of pulse rates of students of the control group showed that only $38 \%$ of the students in the main group structured their classes in accordance with the individual data. These students not only worked in the recommended heartbeat rate zones, but also adhered to the dynamics towards increasing the load. Students of the preparatory group demonstrated a similar result, which is $39 \%$. Most of the students of the special medical group chose a low-intensity load for classes (stretching in combination with breathing exercises, walking); therefore, the results of classes in the zone of "working pulse rate" with progressive dynamics were obtained in the reports of only $26 \%$ of students. 
During the period of distance learning (a little more than two months), the students of the experimental group, whose physical activity was regulated individually, and whose intensity of the load was selected with account of peculiarities of the work of their functional systems, showed a level of adaptation higher than that of students of the control group. Students of both groups noted the interdependence of their mood and wellbeing on the quantity and quality of physical education lessons. Exercises of sufficient intensity improved mood, relieved feelings of anxiety, and increased the positivity of perception of the surrounding environment.

\section{ACKNOWLEDGEMENTS}

The work is performed according to the Russian Government Program of Competitive Growth of Kazan Federal University.

\section{REFERENCES}

Alexandrov, A.Yu. (2020). Motor activity of full-time students of the law university aged 18-22 during the pandemic", Collection of Articles of the Second All-Russian Scientific and Practical Conference "Education, Upbringing and Pedagogy: Traditions, Experience, Innovations", Penza, International Centre for Scientific Cooperation "Science and Education", 117-122. [in Russian].

Allen, J.T., Drane, D.D., Byon, K.K., \& Mohn, R.S. (2010). Sport as a vehicle for socialization and maintenance of cultural identity: International students attending American universities. Sport Management Review, 13(4), 421-434. https://doi.org/10.1016/j.smr.2010.01.004

American College of Sports Medicine. (2006). ACSM's guidelines for exercise testing and prescription, 7th ed., Philadelphia, PA, Lippincott Williams \& Wilkins.

Baevsky, R.M. (1987). Evaluation of the effectiveness of preventive measures based on measuring the adaptation potential of the blood circulatory system. Healthcare of the Russian Federation, 8, 8-10. [in Russian].

Baronenko, V.A., \& Rapoport, L.A. (2013). Health and physical culture of a student: textbook, 2nd ed.., Moscow: Alpha-M: NITs INFRA-M. [in Russian].

Beato, C., \& Silveira, A. (2018). Some Conceptual Basis for Crime Prevention in Brazil and USA: Generic Public Policies and Control Crime Programs. International Journal of Criminology and Sociology, 7, 184-195. https://doi.org/10.6000/1929-4409.2018.07.13

Callaghan, P. (2004). Exercise: A neglected intervention in mental health care?". Journal of Psychiatric and Mental Health Nursing, 11, 476-483. https://doi.org/10.1111/j.1365-2850.2004.00751.x

Cao, W., Fang, Z., Hou, G., Han, M., Xu, X., Dong, J., \& Zheng, J. (2020). The psychological impact of the COVID-19 epidemic on college students in China. Psychiatry research, 112934. https://doi.org/10.1016/j.psychres.2020.112934

Dubbert, P.M. (2002). Physical activity and exercise: Recent advances and current challenges. Journal of Consulting and Clinical Psychology, 70, 526-536. https://doi.org/10.1037/0022-006X.70.3.526

Dunn, A.L., et al., (2002). The DOSE study: A clinical trial to examine efficacy and dose response of exercise as treatment. Controlled Clinical Trials, 23(5), 584-603. https://doi.org/10.1016/S01972456(02)00226-X

Fazleeva, E. V., Shalavina, A. S., Pasmurov, G. I., \& Rahimov, M. I. (2016). Physical training at university as a means of adaptation of foreign students to the study in different cultural environment. The Social Sciences (Pakistan), 11(4), 500-501.

Grutsyak, N.B., \& Grutsyak, V.I. (2010). Physical culture as a powerful factor promoting adaptation of international students at the university. Physical Education of Students, 2, 37-39. [in Russian]. 
Hammami, A., Harrabi, B., Mohr, M., \& Krustrup, P. (2020). Physical activity and coronavirus disease 2019 (COVID-19): specific recommendations for home-based physical training. Managing Sport and Leisure, 1-6. https://doi.org/10.1080/23750472.2020.1757494

Hyland, P., Shevlin, M., McBride, O., Murphy, J., Karatzias, T., Bentall, R., \& Vallières, F. (2020). Anxiety and depression in the Republic of Ireland during the COVID-19 pandemic. PsyArXiv. https://doi.org/10.1111/acps.13219

Il'in, E.P. (2005). Psychophysiology of Human State, Saint Petersburg. Russia: Piter Publishing House. [In Russian].

Karvonen, M.J., Kentala, E., \& Mustala, O. (1957). The effects of training on heart rate; a longitudinal study. Annales Medicinae Experimentalis et Biologiae Fenniae, 35(3), 307-315.

Kershengolts, B.M., \& Kolosova, O.N. (2016). Aging - process of reducing the adaptation potential of the organism as a self-regulating system. International Journal of Applied and Fundamental Research, 9(1), 46-52. [in Russian].

Kholodova, Yu.B. (2020). Features of anxiety associated with the COVID-19 pandemic in different age groups. International Journal of Medicine and Psychology, 3(2), 114-117,. [in Russian].

Levina, I. (2020). Remote educational technologies in the organization of online training. Norwegian Journal of development of the International Science, 42, 66-70. [in Russian].

Lippi, G., Henry, B. M., \& Sanchis-Gomar, F. (2020). Physical inactivity and cardiovascular disease at the time of coronavirus disease 2019 (COVID-19). European Journal of Preventive Cardiology, 2047487320916823. https://doi.org/10.1177/2047487320916823

Mattioli, A.V. et al. (2020). COVID-19 pandemic: the effects of quarantine on cardiovascular risk. European Journal of Clinical Nutrition, 74, 852-855. https://doi.org/10.1038/s41430-020-0646-z

Milko, M.M., \& Guremina, N.V. (2020). Students physical activity investigation in conditions of distance learning and self-isolation. Modern High Technologies, 5, 195-200. [in Russian]. https://doi.org/10.17513/snt.38056

Myers, J. et al. (2004). Fitness versus physical activity patterns in predicting mortality in men. American Journal of Medicine, 117, 912-918. https://doi.org/10.1016/j.amjmed.2004.06.047

Narici, M., (2020). Impact of sedentarism due to the COVID-19 home confinement on neuromuscular, cardiovascular and metabolic health: Physiological and pathophysiological implications and recommendations for physical and nutritional countermeasures. European Journal of Sport Science, 1-22. https://doi.org/10.1080/17461391.2020.1761076

Nikolaou, E., \& Markogiannakis, G. (2017). Greek preschool teachers' perceptions about the effective strategies for bullying prevention in preschool age. International journal of criminology and sociology, 6, 172-177. https://doi.org/10.6000/1929-4409.2017.06.18

Noraseela, M.K., Yusof, A.A., \& Shah, P.M. (2016). Sport activity and cultural integration of international students in University Putra Malaysia. International Journal of Academic Research, 3(2), 1-9.

Özdin, S., \& Bayrak Özdin, Ş. (2020). Levels and predictors of anxiety, depression and health anxiety during COVID-19 pandemic in Turkish society: The importance of gender. International Journal of Social Psychiatry. https://doi.org/10.1177/0020764020927051

Pavlov, S.E. (2001). Fundamental of the theory of adaptation and sports training. Theory and Practice of Physical Culture, 1, 32-38. [in Russian].

Shevlin, M., McBride, O., Murphy, J., Miller, J. G., Hartman, T. K., Levita, L., ... \& Bennett, K. M. (2020). Anxiety, Depression, Traumatic Stress, and COVID-19 Related Anxiety in the UK General Population During the COVID-19 Pandemic. https://doi.org/10.31234/osf.io/hb6ng

Swaim, D. (2012). Heart Education: Strategies, Lessions, Science, and Technology for Cardiovascular Fitness, USA, Human Kinetics. 
Tumakov, D., Fazleeva, E., Akberov, R., \& Valeeva, A. (2018). Adaptation to physical activities by international students at a Russian university. South African Journal for Research in Sport, Physical Education and Recreation, 40(1), 157-166.

Tumakov, D., Fazleeva, E., Valeeva, A., \& Akberov, R. (2017). A mathematical model for influence of physical exercises on psychophysiological adaptation of international students to learning performance at universities. Journal of Pharmacy Research, 11(11), 1330-1335.

Tumakov, D., Fazleeva, E., Valeeva, A., \& Akberov, R. (2019). Mathematical Model Of PsychoPhysiological Adaptation Of International Students Through Dosed Physical Activities. International Transaction Journal of Engineering, Management, \& Applied Sciences \& Technologies, 10(16), 10A16C.

Tumakov, D., Godovykh, C., \& Valeeva, A. (2018). Mathematical model of socio-psychological adaptation through a person's interaction with the environment. Herald National Academy of Managerial Staff of Culture and Arts, 3, 310-318.

Vasenkov, N.V., \& Fazleeva, E.V. (2013). Hypokinesia as one of causes of student health deterioration. Bulletin of the Scientific Center for Safety of Life, 1(15), 50-54. [In Russian].

Zaitseva, T.V. (2020). The impact of physical exercise on the human organism during self-isolation. Competition for Research Papers: Current Issues of Modern Science, Ufa, 247-252. [in Russian].

Zhao, Y., An, Y., Tan, X., \& Li, X. (2020). Mental Health and Its Influencing Factors among Self-Isolating Ordinary Citizens during the Beginning Epidemic of COVID-19. Journal of Loss and Trauma, 1-14. https://doi.org/10.1080/15325024.2020.1761592

\section{@) $\Theta \Theta \Theta$}

This work is licensed under a Attribution-NonCommercial-NoDerivatives 4.0 International (CC BY-NC-ND 4.0). 